\title{
Medicamento para tratamento da hepatite C: da aprovação do medicamento genérico Sofosbuvir pela Anvisa às dificuldades sociais e comerciais.
}

\author{
Medicine for treatment of hepatitis C: From the approval of generic \\ drug Sofosbuvir by Anvisa to social and commercial difficulties.
}

\author{
Anselmo Gomes de OLIVEIRA; \\ Dâmaris SILVEIRA \\ Editores-chefe
}

A hepatite $\mathrm{C}$, uma infecção viral causada pelo vírus $\mathrm{HCV}$, caracterizada por icterícia, febre, náusea, dor abdominal, urina e fezes escuras, dentre outros sintomas (1). Em $80 \%$ dos casos a infecção persiste por mais de seis meses e, nestes casos, a doença se torna crônica e, em $20 \%$ dos casos pode evoluir para cirrose hepática e câncer de fígado (2). A hepatite $\mathrm{C}$ é um problema de saúde pública global, que possui estimativa de cerca de 70 milhões de indivíduos com a infecção crônica, sendo que cerca d 400.000 indivíduos morrem a cada ano, principalmente devido a cirrose ou carcinoma hepatocelular (1). Entre as causas mais graves de transmissão da doença estão a transfusão de sangue e o compartilhamento de diversos tipos de materiais, como por exemplo agulhas de injeção, ou por contato com fluídos biológicos, particularmente da mucosa oral (3). A taxa de incidência da doença no Brasil em 2017 foi de 11,9 casos por 100 mil habitantes. Entretanto, mais de um milhão de pessoas tiveram contato com o vírus do tipo $\mathrm{C}(4,5)$.

O plano do Ministério da Saúde para eliminação da doença, alinhado com as metas da Organização Mundial da Saúde (OMS), é de tratar cerca de 19 mil pessoas em 2018, e a partir de 2019 cerca de 50 mil pacientes por ano, até 2024. A partir de 2025, serão cerca de 32 mil novos tratamentos por ano até 2030, quando espera-se que a mortalidade pela hepatite $\mathrm{C}$ seja reduzida para $65 \%$. Atualmente, o tratamento disponível no Sistema Único de Saúde (SUS) e fornecido a todos os pacientes infectados, qualquer que seja o grau de lesão do fígado permite a chance de cura em mais de $90 \%$ dos casos (5).

Em maio de 2018, a Agencia Nacional de Vigilância Sanitária (Anvisa) publicou o registro inédito do primeiro medicamento genérico do sofosbuvir (6), um antiviral de ação direta, que atua como inibidor da polimerase NS5B, uma enzima essencial para a multiplicação do vírus $\mathrm{HCV}$ no organismo humano. $\mathrm{O}$ sofosbuvir é capaz de curar a hepatite $\mathrm{C}$ em cerca de $95 \%$ dos casos, portanto muito mais eficaz do que os medicamentos existentes até 2014, cujas eficiências das terapias chegavam em cerca de $50 \%$ dos casos tratados (7). O registro do medicamento genérico sofosbuvir foi concedido à empresa Blanver Farmoquímica e Farmacêutica S/A, por meio de um convênio entre essa empresa e Farmanguinhos-Fiocruz (6). O medicamento referência do sofosbuvir está no mercado com o nome de Sovaldi, registrado pela empresa Gilead Sciences Farmacêutica do Brasil Ltda, de origem norte americana.

Em julho de 2018, o Ministério da Saúde realizou uma tomada de preços do sofosbuvir sendo que Farmanguinhos-Fiocruz ofereceu o medicamento genérico por US\$ 8,50 por comprimido, enquanto que e a Giled ofereceu o medicamento de marca por US\$ 34,32. A combinação entre o sofosbuvir (Fiocruz) e daclatasvir de marca (Bristol), utilizada pelo Ministério da Saúde, corresponde, atualmente, a um custo de US\$ 6.905,00. Mas pela proposta mais recente, o Ministério da Saúde pagaria US\$ 1.506,00 (Fiocruz e Bristol), o que implicaria numa economia de mais de 1 bilhão de reais. No contexto dessas controvérsias, a Gilead solicitou o registro da patente do sofosbuvir no Brasil, o que poderia bloquear o medicamento genérico no país. A questão aqui parece tratar de fazer prevalecer a lógica de mercado, pois a empresa farmacêutica faturou cerca de US\$ 55 bilhões com medicamentos contra hepatite $\mathrm{C}$ desde 2014, com o lançamento do Sovaldi, cujo tratamento 
custava na época cerca de US\$ 84 mil (8). Mas, em tempos dos medicamentos genéricos no Brasil, por que não usá-los? Se, no caso dos genéricos para tratamento do HIV, a situação foi, acertadamente, resolvida (9), o que impede o Brasil de seguir os mesmos critérios com os medicamentos para tratamento da hepatite C? Parece evidente que para a sociedade brasileira a competição com genéricos poderia proporcionar a cura mais eficaz e facilitada para cerca de 700 mil pessoas com hepatite $\mathrm{C}$ no país. A Fiocruz já se manifestou que o sofosbuvir genérico teve a bioequivalência testada e que tem plena capacidade para produzi-lo, como fez com os genéricos anti-HIV (10).

O Brasil poderia ter tomado uma decisão social humanitária com relação ao medicamento, que permitisse maior acesso dos brasileiros ao tratamento com sofosvubir, como fez a Argentina que não reconheceu a patente e produz os genéricos (11); o Egito, que negou a patente, fez um acordo e o governo passou a produzir o genérico (12), já tendo tratado cerca de 1 milhão de pessoas doentes; e a India, onde a Gilead fez um acordo permitindo que os fabricantes produzam o genérico pagando uma licença, mas proibindo a exportação para países com renda média e muitos casos da doença (13). Contudo, no Brasil, a solicitação do pedido de patente do sofosbuvir, pela Gilead, foi deferida pelo Instituto Nacional de Propriedade Intelectual (INPI) (14). O medicamento, que vem revolucionando o tratamento da hepatite $\mathrm{C}$ permitindo a cura de pacientes e reduzindo significativamente a demanda pelo transplante de fígado poderá ter sua versão genérica barrada.

A Fiocruz recebeu com surpresa essa decisão do INPI, pois avalia que não há os requisitos de novidade e atividade inventiva no pedido de patente. Também não foi apresentada a descrição de invenção, de forma que se conseguisse reproduzir o medicamento reivindicado. Essa descrição é um dos requisitos que devem ser observados para a concessão de patente. Ainda, pode ser destacado que de 126 reivindicações iniciais desse pedido de patente da Gilead, 124 foram canceladas pois a empresa adotou a estratégia de "evergreening" para o patenteamento do medicamento sofosbuvir, ou seja, foram depositados mais de 21 pedidos sequenciais de invenções incrementais em todo o mundo, com o único objetivo de prolongar o tempo de exclusão de empresas concorrentes que tivessem pretensão de produzir e comercializar medicamentos genéricos. No caso do sofosvubir, a estratégia só prejudica as políticas públicas do país, uma vez que não há de fato uma inovação, mas um novo pedido de patente com objetivo de estender por mais tempo o domínio sobre o mercado para aquele fármaco inicialmente protegido (14).

Os cálculos do Ministério da Saúde indicam que o custo de cada tratamento de hepatite $\mathrm{C}$, que dura 84 dias, seria de pouco mais de R\$ 5 mil com o medicamento genérico nacional, mas que com os medicamentos dos laboratórios privados o custo por paciente já chegou ao patamar de US\$ 84 mil. A Organização Médicos Sem Fronteiras (MSF) avaliou que a decisão do INPI limita $\mathrm{o}$ acesso à cura de pacientes com hepatite $\mathrm{C}$ no Brasil e que havia argumentos sólidos, baseados no interesse público, para negar a concessão da patente (15).

O INPI informou que o processo "seguiu todas as etapas e prazos previstos na Lei”. Mas, como explicar que no Brasil, onde um processo de patente tem demorado meros 10-11 anos (16), e que o INPI possui um plano de reduzir em 2019 o tempo médio de concessão de 10,9 anos para 8,6 anos para patentes de invenção (17), um pedido patente de uma farmacêutica multinacional pôde demorar somente alguns meses? Em se tratando de medicamento com tal especificidade, que competência teria o INPI para avaliar os detalhes técnicos e os detalhes biológicos de seu efeito no ser humano? De outro lado, por que as instâncias governamentais, câmara dos deputados e senado federal, que foram tão sensíveis aos aspectos sociais e humanitários da fosfoetanolamina, que não oferecia mínimas condições para ser considerada "medicamento", não usaram o mesmo critério no caso de sofosvubir no tratamento da hepatite C? São perguntas que não querem calar...

Caso a patente persista no Brasil, mesmo diante de todas as incoerências já explicitadas, há - ainda - a saída do licenciamento compulsório do sofosbuvir como medicamento genérico, cuja tecnologia já existe em nosso país, assim como a infraestrutura física para sua produção industrial.

Ainda que não seja definitiva, na decisão acertada da Justiça Federal do Distrito Federal, que deferiu o pedido de liminar da presidenciável Marina Silva e anulou a patente sobre o sofosbuvir, o juiz argumentou que ao aprovar a patente do sofosbuvir para a indústria farmacêutica americana Gilead, o INPI contraria a manifestação do Conselho Nacional de Saúde (CNS) e poderia inviabilizar o cumprimento da meta assumida pelo Brasil de erradicar a doença até 2030 (18). A Ordem dos Advogados do Brasil (OAB) se manifestou favorável à obtenção de uma licença compulsória para a fabricação do medicamento genérico sofosbuvir, o que permitiria que os genéricos possam ser produzidos no Brasil (19). 
Dessa forma a empresa Gilead não perderia a sua patente e a licença contemplaria o interesse público permitindo o acesso da população ao tratamento da hepatite
C. Pelo bem da saúde pública, fica o desejo de que uma decisão a favor da população brasileira seja tomada em um curto espaço de tempo.

\section{REFERÊNCIAS}

1. WHO. Hepatitis C. World Health Organization. Fact sheets. 18 de julho de 2018. http://www.who.int/en/news-room/fact-sheets/detail/hepatitis-c

2. Brasil. Agência Nacional de Vigilância Sanitária. Anvisa aprova novo genérico para tratamento da hepatite C. http://portal.anvisa.gov.br/rss///asset_publisher/Zk4q6UQCj9Pn/content/id/4442240. Acesso em 26/09/2018

3. Zibbell JE, Asher AK, Patel RC, Kupronis B, Iqbal K, Ward JW, et al. Increases in acute hepatitis $C$ virus infection related to a growing opioid epidemic and associated injection drug use, United States, 2004 to 2014. Amer J Public Health. 2018;108(2):175-81. DOI: 10.2105/ AJPH.2017.304132

4. BRASIL. Ministério da Saúde. Brasil apresenta plano para erradicar hepatite C até 2030. http://www.brasil.gov. br/noticias/saude/2017/11/brasil-apresenta-plano-para-erradicar-hepatite-c-ate-2030

5. WHO. Close to 3 million people access hepatitis $\mathrm{C}$ cure. World Health Organization. 31 de outubro de 2018. http://www.who.int/news-room/detail/31-10-2017-close-to-3-million-people-access-hepatitis-c-cure

6. BRASIL. Resolução RE 1225. Agência Nacional de Vigilância Sanitária. 17 de maio de 2018. D.O.U.Suplemento, 21 de maio de 2018. http://pesquisa.in.gov.br/ imprensa/jsp/visualiza/index.jsp?data $=21 / 05 / 2018 \&$ jornal $=531$ \&pagina $=26 \&$ total Arquivos $=100$

7. Bourlière M, Gordon SC, Flamm SL, Cooper CL, Ramji A, Tong M, et al. Sofosbuvir, velpatasvir, and voxilaprevir for previously treated HCV infection. New England J Med. 2017;376(22):2134-46.

8. Decker S; Koons C. Gilead's patente on hepatitis C drug challenged by consumer group. Bloomberg. 25 de outubro de 2017. https://www.bloomberg.com/news/articles/2017-10-25/gilead-patents-on-sovaldi-drug-challenged-by-consumer-group

9. Loyola MA. Medicamentos e saúde pública em tempos de AIDS: metamorfoses de uma política dependente. Ciência \& Saúde Col. 2008;13(suppl):763-78.

10. FIOCRUZ. Farmanguinhos divulga nota sobre medicamento contra hepatite C. Agência Fiocruz de notícias. 20 de setembro de 2018. https://agencia.fiocruz.br/farmanguinhos-divulga-nota-sobre-medicamento-contra-hepatite-c
11. MMA. Argentina: patente rejected on hepatites $\mathrm{C}$ drug, sofosbuvir. Make Medicine Affordable. 8 de dezembro de 2017. http://makemedicinesaffordable.org/en/argentina-patent-rejected-on-hepatitis-c-drug-sofosbuvir/

12. Loewy, MA. Anunciado o desenvolvimento de tratamento acessível de hepatite C na América Latina. Medscape. 10 de abril de 2018. https://portugues.medscape.com/verartigo/6502221

13. MSF. Patent challenge hearing on Gilead hepatitis $\mathrm{C}$ drug sofosbuvir starts in India. Medecins sans frontiers. 26 de fevereiro de 2016. https://www.msfindia.in/patent-challenge-hearing-gilead-hepatitis-c-drug-sofosbuvir-starts-india

14. Oliveira V. A Fiocruz recebe com surpresa a notícia do deferimento de um dos pedidos de patente do medicamento sofosbuvir para o tratamento da hepatite $\mathrm{c}$. http:// www.far.fiocruz.br/2018/09/a-fiocruz-recebe-com-surpresa-a-noticia-do-deferimento-de-um-dos-pedidos-de-patente-do-medicamento-sofosbuvir-indicado-para-o-tratamento-da-hepatite-c/

15. Laboissiere P. Brasil pode economizar 1 bilhão com genérico contra hepatite $\mathrm{C}$. Empresa Brasil de Comunicação - EBC. 09 de agosto de 2018. http://agenciabrasil. ebc.com.br/saude/noticia/2018-08/brasil-pode-economizar-r-1-bilhao-com-generico-contra-hepatite-c

16. Alves NR. País demora 11 anos para aprovar patentes. Estadão. 24 de maio de 2015. https://economia.estadao. com.br/noticias/geral,pais-demora-11-anos-para-aprovar-patentes, 1693427.

17. Grael F. Demora na aprovação de patentes é obstáculo para a a inovação no Brasil. Inovação. Rev. Eletron. de P, D \& I. 2 de julho de 2015. https://www.inovacao.unicamp.br/noticias/demora-na-aprovacao-de-patentes-e-obstaculo-para-a-inovacao-no-brasil/.

18. Folha de São Paulo. Decisão liminar anula patente de remédio contra hepatite $\mathrm{C}$ no país. 24 de setembro de 2018. https://www1.folha.uol.com.br/cotidiano/2018/09/decisao-liminar-quebra-patente-de-remedio-contra-a-hepatite-c-no-pais.shtml

19. Agencia AIDS. OAB afirma que cobrará licença compulsória do sofosbuvir. 25 de setembro de 2018. http:// agenciaaids.com.br/noticia/oab-afirma-que-cobrara-licenca-compulsoria-do-sofosbuvir/ 